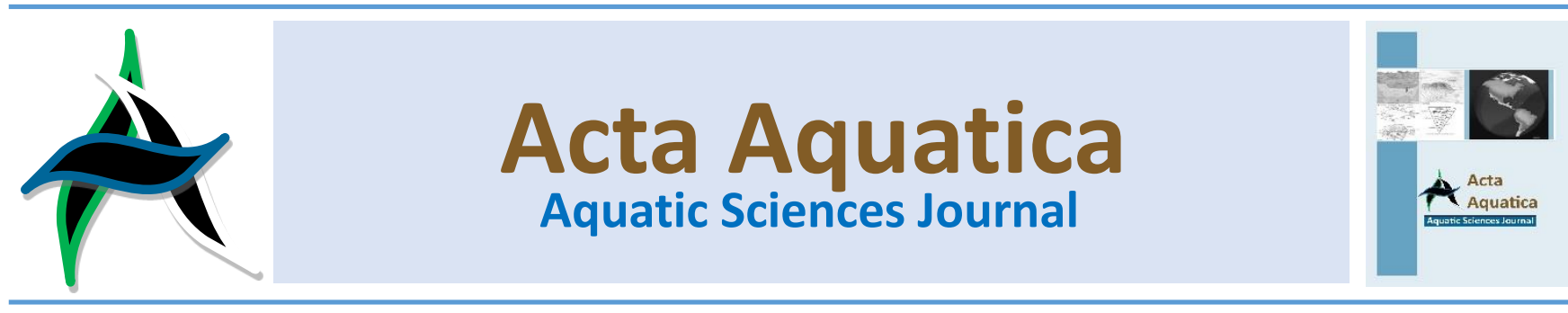

\title{
Pengaruh penggunaan jenis wadah yang berbeda terhadap pertumbuhan dan kelangsungan hidup ikan betutu (Oxyeleotris marmorata Blkr.)
}

\section{The effect of different types of containers on growth and survival rate of sand goby (Oxyeleotris marmorata Blkr.)}

\author{
Hadra Fi Ahlina a ${ }^{\text {, Yoyon Riono }}{ }^{\text {b }}$ dan Syaiful Ramadhan Harahap ${ }^{\text {a, * }}$ \\ a Program Studi Budidaya Perairan, Universitas Islam Indragiri, Indragiri Hilir, Indonesia \\ ${ }^{\text {b }}$ Program Studi Agroteknologi, Universitas Islam Indragiri, Indragiri Hilir, Indonesia
}

\begin{abstract}
Abstrak
Ikan betutu Oxyeleotris marmorata merupakan ikan lokal potensial menjadi komoditas budidaya. Performa pertumbuhan dan kelangsungan hidup dapat ditingkatkan dengan mengembangkan wadah budidaya. Tujuan penelitian adalah mengetahui jenis wadah budidaya yang optimal dalam mendukung pertumbuhan dan kelangsungan hidup. Perlakuan yang di uji adalah kolam tanah, kolam hapa dan kolam terpal berukuran $3 \mathrm{~m} \times 2 \mathrm{~m} \times 1 \mathrm{~m}$. Ukuran benih yang digunakan $15 \pm 1,39 \mathrm{~cm}$ dengan bobot $250,04 \pm 1,70 \mathrm{~g}$ dengan padat tebar 25 ekor/kolam. Selama 120 hari masa pemeliharaan, pakan yang diberikan adalah ikan rucah sebanyak $30 \%$ dari bobot tubuh dengan frekwensi $2 x$ sehari. Hasil penelitian menunjukkan perbedaan jenis wadah berpengaruh nyata terhadap pertambahan bobot dan laju pertumbuhan spesifik, namun tidak berpengaruh nyata terhadap kelangsungan hidup. Pertambahan bobot terbaik terdapat pada perlakuan jenis wadah kolam tanah sebesar $53,86 \pm 1,10 \mathrm{~g}$ dengan laju pertumbuhan spesifik $0,45 \pm 0,010$ \%bobot tubuh/hari dan kelangsungan hidup $85,33 \pm 6,11 \%$. Kualitas air pada seluruh wadah pemeliharaan masih mendukung pertumbuhan dan kelangsungan hidup. Hasil penelitian ini dapat dijadikan informasi dasar dalam pemilihan wadah budidaya yang efektif dan efisien dalam pengembangan budidaya ikan betutu secara optimal.
\end{abstract}

\begin{abstract}
Sand goby (Oxyeleotris marmorata. Blkr) is a potential fish species for aquaculture in Indonesia. However, the growth and survival rate performance can be improved by developing cultivation containers. The research objective was to determine the optimal type of cultivation container to produce high growth and survival rate. The ponds treatments used in this experiment were soil pond, hapa pond and tarpaulin pond with measuring $3 \mathrm{~m} \times 2 \mathrm{~m} \times 1 \mathrm{~m}$. The initial fish length average was $15 \pm 1.39 \mathrm{~cm}$, with the initial body weight average of $250.04 \pm 1.70 \mathrm{~g}$ with the stocking density of 25 individual/pond. During 120 days of the rearing period, the fish were fed with trash fish with a proportion of $30 \%$ of body weight with the frequency of feeding $2 x$ a day. The results showed differences in the type of container significantly affected weight gain and specific growth rates but did not significantly affect survival rate. The best weight gain was found in the treatment of soil pond containers at $53.86 \pm 1.10 \mathrm{~g}$ with a specific growth rate of $0.45 \pm 0.010 \%$ body weight/day and survival rate of $85.33 \pm 6.11 \%$. Water quality in all containers still supports growth and survival rate. The results of this study can be used as necessary information in the selection of effective and efficient aquaculture containers to produce optimal sand goby culture.
\end{abstract}

Keywords: sand goby; growth; survival rate; container

\footnotetext{
* Corresponding author: Program Studi Budidaya, Perairan Fakultas Pertanian, Universitas Islam Indragiri. Jl. Provinsi Parit 1 Kec. Tembilahan Hulu, Kabupaten Indragiri Hilir, Provinsi Riau, 29213, Indonesia. Telp: +62.768 .324918$

e-mail: syaiful.r.harahap@gmail.com

doi: https://doi.org/10.29103/aa.v6i2.1666
}

\section{Pendahuluan}

Ikan Betutu (Oxyeleotris marmorata. Blkr.) merupakan salah satu komoditas ikan air tawar yang sangat potensial di Indonesia. Permintaan terhadap ikan betutu semakin meningkat baik di dalam maupun luar negeri seperti Malaysia, Singapura dan Hongkong. Kabupaten Indragiri Hilir adalah daerah penghasil ikan betutu di Provinsi Riau yang menjadi komoditas air tawar andalan. Harga ikan betutu ukuran konsumsi adalah Rp. $125.000,-/ \mathrm{kg}$, sedangkan harga Ikan Betutu untuk ekspor dapat 
mencapai Rp. 300.000,-/kg (Kudsiah dan Nur, 2008). Tingginya harga Ikan Betutu disebabkan cita rasa yang lezat serta dagingnya yang putih dan empuk. Dagingnya mengandung protein (9-22\%), lemak (0,1-20\%), mineral (1-3\%), vitamin, lecithin, guanine dan sedikit kandungan kolesterol (Arief et al., 2009).

Permintaan pasar yang cukup tinggi terhadap ikan ini menyebabkan tingkat eksploitasi lebih cepat dibandingkan dengan rekruitmennya. Hal ini disebabkan permintaan ikan betutu (benih dan ukuran konsumsi) masih dipenuhi dari hasil tangkapan di perairan umum, bila keadaan ini terus berlanjut, dikhawatirkan akan merusak kelestariannya. Kondisi ini menuntut adanya penyediaan produksi dalam jumlah yang besar dan berkesinambungan salah satunya melalui kegiatan budidaya. Pada budidaya ikan betutu, faktor yang perlu diperhatikan adalah pertumbuhan yang lambat dan tingkat kelangsungan hidup yang rendah. Laju pertumbuhan dan tingkat kelangsungan hidup ikan betutu sangat dipengaruhi oleh faktor internal dan eksternal ikan itu sendiri. Faktor internal meliputi sifat genetik sedangkan faktor eksternal merupakan faktor yang berasal dari lingkungan. Salah satu faktor lingkungan yang berperan dalam budidaya ikan betutu adalah pemilihan jenis wadah budidaya yang tepat. Wadah budidaya merupakan ruang tempat berinteraksinya antara ikan sebagai biota budidaya dengan air sebagai media budidaya untuk hidup dan berkembang. Jenis wadah budidaya sangat menentukan hasil dari interaksi antara ikan dan air. Indikator yang mudah terlihat dari hasil interaksi antara ikan dengan air adalah pertumbuhan ikan dan kualitas air selama kegiatan budidaya.

Terdapat beberapa jenis wadah dalam kegiatan budidaya ikan, namun yang sering digunakan untuk budidaya ikan-ikan air tawar adalah wadah budidaya berupa kolam. Beberapa pengembangan jenis kolam yang sering digunakan dalam kegiatan budidaya ikan air tawar antara lain kolam tanah, kolam beton, kolam hapa dan kolam terpal (Satyani dan Priyono, 2012).

Penelitian mengenai pertumbuhan dan kelangsungan hidup ikan betutu telah banyak dilakukan, namun penelitian terkait pengaruh perbedaan jenis wadah budidaya terhadap pertumbuhan dan kelangsungan hidup ikan betutu secara spesifik relatif sangat jarang dilakukan. Penelitian ini bertujuan untuk mengetahui pengaruh jenis wadah budidaya kolam tanah, kolam hapa dan kolam terpal terhadap pertumbuhan dan kelangsungan hidup ikan betutu. Informasi terkait wadah budidaya yang efektif dan efisien dalam mendukung pertumbuhan dan kelangsungan hidup ikan betutu akan sangat bermanfaat dalam pengembangan budidaya ikan betutu secara optimal.

\section{Bahan dan metode}

\subsection{Bahan dan alat}

Penelitian ini dilakukan selama 120 hari yang bertempat di Kolam Percobaan Program Studi Budidaya Perairan Fakultas Pertanian Universitas Islam Indragiri. Perlatan yang digunakan dalam penelitian terdiri dari alat tulis, serok, wadah budidaya berupa kolam tanah, kolam hapa dan kolam terpal, thermometer, DO meter, $\mathrm{pH}$ meter dan ammonia test kit. Sedangkan bahan yang digunakan terdiri dari; ikan betutu sebagai ikan uji dan ikan rucah sebagai pakan ikan uji selama berlangsungnya penelitian.

\subsection{Metode penelitian}

Metode penelitian yang digunakan adalah metode eksperimental. Rancangan percobaan yang digunakan dalam penelitian ini adalah Rancangan Acak Lengkap (RAL) non faktorial. Perlakuan dalam percobaan ini adalah perbedaan jenis wadah budidaya dengan tiga kali ulangan. Adapun perlakuan yang digunakan adalah:

Perlakuan A : Perlakuan jenis wadah kolam tanah Perlakuan B : Perlakuan jenis wadah kolam hapa Perlakuan C : Perlakuan jenis wadah kolam terpal

\subsection{Persiapan wadah dan pemeliharaan ikan betutu}

Kegiatan pemeliharaan ikan uji dimulai dengan kegiatan persiapan media wadah budidaya berupa sembilan kolam dengan ukuran (PxLxT) 3×2x1 m, yang terdiri dari tiga unit kolam tanah, tiga unit kolam hapa dan tiga unit kolam terpal. Sebelum instalasi kolam dengan hapa dan terpal, pada seluruh kolam dilakukan pengeringan, pengapuran dengan kapur karbonat $\left(\mathrm{CaCO}_{3}\right)$ dan pemupukan dengan pupuk NPK. Selanjutnya jaring hapa dan terpal yang akan di instalasi pada kolam tanah dilakukan proses desinfeksi dengan cara di bilas menggunakan air dan dikeringkan selama 1 hari. Selanjutnya dilakukan proses intalasi unit percobaan berupa kolam hapa dan kolam terpal dengan ukuran yang disesuaikan dengan kolam tanah yang dilanjutkan dengan melakukan pengisian air dengan ketinggian \pm $75 \mathrm{~cm}$ dari dasar kolam pada seluruh unit wadah percobaan dan dibiarkan selama 3 hari.

Aklimatisasi awal ikan uji dengan merendam wadah plastik ke dalam kolam selama \pm 2 jam pada pagi hari dengan tujuan agar ikan uji dapat mengadaptasi suhu pada kolam percobaan. Penebaran Ikan uji dilakukan pagi hari saat suhu rendah untuk menstabilkan kondisi air sehingga ikan uji mudah beradaptasi (Saparinto, 2009). Aklimatisasi lanjutan dilakukan 1 minggu dengan pemberian pakan dua kali sehari secara $a d$ satiasi. Pengambilan data bobot awal ikan uji dilakukan secara acak terhadap 8 ekor/wadah (30\% dari padat tebar) yang dilakukan setelah 24 jam proses pemuasaan ikan uji selesai dilakukan.

Ikan uji adalah Ikan Betutu dengan panjang rata-rata $15 \pm 1,39 \mathrm{~cm}$ dan bobot rata-rata $250,04 \pm 1,70 \mathrm{~g}$ yang berasal dari hasil tangkapan nelayan di perairan sekitar Desa Teluk Dalam, Kabupaten Indragiri Hilir, Riau. Ikan uji dipelihara selama 120 hari dengan padat penebaran 25 ekor/wadah. Pakan yang digunakan berupa cincangan Ikan Rucah dengan ukuran disesuaikan dengan bukaan mulut ikan berdasarkan Harahap dan Yusapri (2015). Interval pemberian pakan merujuk pada frekwensi pemberian pakan optimal ikan betutu menurut Ahlina et al. (2018) yaitu dengan frekwensi $2 \mathrm{kali} /$ hari yang dilakukan pada interval waktu 8 jam yaitu pada pukul 08.00 pagi dan pukul 16.00 sore. Persentase pakan yang diberikan sebesar $30 \%$ dari total bobot tubuh dengan durasi waktu pemberian pakan selama 30 menit (Arief et al., 2009).

\subsection{Parameter pengamatan}

\subsubsection{Laju pertumbuhan ikan betutu}

Pengamatan pertumbuhan dilakukan setiap 14 hari sekali secara acak sebanyak 8 ekor/wadah (30\% dari padat tebar per wadah). Pengamatan dilakukan dengan cara diukur secara manual. Laju pertumbuhan ikan betutu diperoleh dari pengukuran bobot yang dilakukan dengan mengisi air kedalam wadah kemudian ditimbang banyaknya air, dan timbangan analitik dinolkan kembali. Kemudian dilanjutkan dengan memasukkan ikan betutu yang telah di sampling ke dalam wadah yang berisi air untuk di timbang bobot tubuhnya. Pertambahan bobot ikan Betutu dihitung menggunakan formulasi Hariati 
dalam Arief et al. (2009), sedangkan laju pertumbuhan spesifik ikan betutu di hitung menggunakan formulasi Elliot dan Hurley (1995) sebagai berikut:

\section{Pertambahan bobot}

$$
(G)=W t-W o
$$

Keterangan:

$G=$ Pertumbuhan bobot $(\mathrm{g})$

$W_{t}=$ Bobot rata-rata akhir penelitian (g)

$W_{0}=$ Bobot rata-rata awal penelitian $(\mathrm{g})$

(Sumber : Hariati dalam Arief, et al., 2009).

Laju pertumbuhan spesifik

$$
(S G R)=\frac{\ln W t-\ln W o}{t} \times 100 \%
$$

Keterangan:

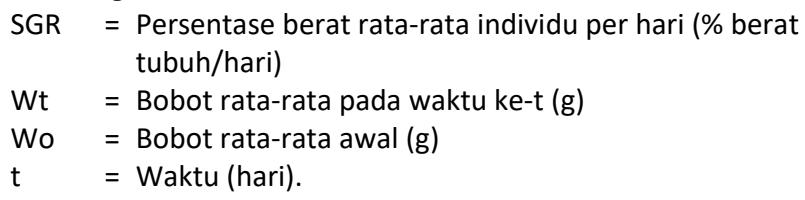

(Sumber: Elliot dan Hurley, 1995).

\subsubsection{Kelangsungan hidup ikan betutu}

Kelangsungan hidup ikan betutu dilakukan pada awal dan akhir penelitian. Perhitungan nilai kelangsungan hidup mengacu pada persamaan (Effendie, 2002) dengan menggunakan rumus:

$$
\operatorname{SR}(\%)=\frac{\mathrm{Nt}}{\mathrm{No}} \times 100
$$

Keterangan:

SR = Survival rate/Kelulushidupan (\%)

$\mathrm{Nt}=$ Jumlah ikan uji di akhir pemeliharaan (ekor)

No $=$ Jumlah ikan uji di awal pemeliharaan (ekor)

\subsubsection{Kualitas air}

Pengamatan terhadap kualitas air pada seluruh unit perlakuan penelitian dilakukan secara in situ terhadap beberapa parameter kualitas air meliputi parameter suhu, pH dan oksigen terlarut (DO). Pengukuran dilakukan setiap hari yaitu jam 08.00 WIB kecuali pada parameter suhu yang dilakukan sebanyak 2 kali sehari yaitu pada jam 08.00 WIB dan jam 16.00 WIB. Metode pengamatan parameter kualitas air dapat dilihat pada Tabel 1.

Tabel 1

Metode pengamatan kualitas air

\begin{tabular}{lccc}
\hline Parameter & Metode & Kisaran optimal & Sumber \\
\hline Suhu & Termometer & $24-28^{\circ} \mathrm{C}$ & Azwar et al. (2003) \\
pH & pH meter & $5,5-7,5$ & Kordi (2013) \\
DO & DO meter & $>3 \mathrm{mg} / \mathrm{L}$ & Kordi (2013) \\
Ammonia & Ammonia test kit & $<2 \mathrm{mg} / \mathrm{L}$ & Hidayah (1993) \\
\hline
\end{tabular}

\subsection{Analisa data}

Data hasil pengamatan ditabulasikan dalam tabel dan grafik, Analisis data menggunakan Rancangan Acak non faktorial. Kemudian dianalisa dengan uji $F$ (anova). Apabila nilai $F$ hitung $>$ nilai $F$ tabel menunjukkan adanya pengaruh nyata antar perlakuan, maka analisis data dilanjutkan dengan Tukey test dengan menggunakan aplikasi SPSS ver. 17.0.

\section{Hasil dan pembahasan}

\subsection{Hasil}

\subsubsection{Pertambahan bobot ikan betutu (Oxyeleotris marmorata Blkr.)}

Pertambahan bobot adalah gambaran perubahan bobot rata-rata individu pada tiap perlakuan dari awal hingga akhir pemeliharaan yang ditentukan berdasarkan selisih bobot akhir dengan bobot awal pemeliharaan (Effendie, 2002). Hasil pengamatan terhadap rata-rata bobot awal, bobot akhir serta pertambahan bobot ikan betutu disajikan pada Tabel 2 .

Tabel 2

Rata-rata bobot awal, bobot akhir serta pertambahan bobot ikan betutu (Oxyeleotris marmorata. Blkr.) selama 120 hari pengamatan.

\begin{tabular}{lccc}
\hline Perlakuan & $\begin{array}{c}\text { Bobot awal (g) } \\
\text { Rata-rata } \pm \text { sd }\end{array}$ & $\begin{array}{c}\text { Bobot akhir (g) } \\
\text { Rata-rata } \pm s d\end{array}$ & $\begin{array}{c}\text { Pertambahan bobot }(\mathrm{g}) \\
\text { Rata-rata } \pm \text { sd }\end{array}$ \\
\hline A & $250,02 \pm 2,36$ & $303,87 \pm 2,55$ & $53,86 \pm 1,10^{\text {a) }}$ \\
B & $250,07 \pm 1,47$ & $300,63 \pm 2,74$ & $50,56 \pm 1,65^{\text {a) }}$ \\
C & $250,04 \pm 1,26$ & $298,29 \pm 1,73$ & $48,26 \pm 1,47^{\text {a) }}$ \\
\hline
\end{tabular}

Keterangan: $\mathrm{A}=$ kolam tanah; $\mathrm{B}=$ kolam hapa; $\mathrm{C}=$ kolam terpal; $\pm \mathrm{SD}=$ standar deviasi yang merupakan range dari rata-rata pengulangan masing-masing perlakuan; huruf superskrip a) = menunjukkan adanya perbedaan signifikan berdasarkan uji Anova yang dilanjutkan dengan Tukey test $(\alpha=0,05)$.

Hasil pengamatan terhadap pertambahan bobot ikan betutu di dapati pertambahan bobot ikan betutu tertingg terdapat pada perlakuan A (kolam tanah) dengan pertambahan bobot rata-rata $53,86 \pm 1,10 \mathrm{~g}$, di ikuti oleh perlakuan B (kolam hapa) dengan pertambahan bobot rata-rata $50,56 \pm 1,65 \mathrm{~g}$ dan terendah pada perlakuan C (kolam terpal) dengan pertambahan bobot rata-rata $48,26 \pm 1,47 \mathrm{~g}$.

Hasil Anova menunjukkan bahwa penggunaan jenis wadah yang berbeda berpengaruh signifikan terhadap pertambahan bobot ikan betutu ( $F$ hitung 31,95 $>F$ tabel $(0,05)$ $5,78)$. Hasil uji lanjut menggunakan Tukey test menunjukkan bahwa seluruh perlakuan penelitian menunjukkan adanya perbedaan yang signifikan $(\alpha=0,05)$.

Persentase laju pertumbuhan harian diketahui dengan cara menghitung laju pertumbuhan spesifik ikan betutu. Laju pertumbuhan spesifik merupakan laju pertumbuhan harian dalam satuan persen (\%) yang dapat menjelaskan kemampuan ikan dalam memanfaatkan nutrien dan mengkonversinya menjadi energi sehingga dapat digunakan dalam proses metabolisme dasar, pergerakan, produksi organ seksual, perawatan bagian-bagian tubuh serta pergantian sel-sel yang telah rusak dan kelebihannya digunakan untuk pertumbuhan (Arief et al., 2009). Laju pertumbuhan spesifik ikan betutu dapat dilihat pada Tabel 3.

Tabel 3

\begin{tabular}{|c|c|}
\hline Perlakuan & $\begin{array}{l}\text { Laju Pertumbuhan Spesifik (\%berat tubuh/hari) Rata- } \\
\text { rata } \pm S D\end{array}$ \\
\hline A & $0,45 \pm 0,010^{\mathrm{a})}$ \\
\hline B & $\left.0,42 \pm 0,013^{a}\right)$ \\
\hline $\mathrm{C}$ & $0,40 \pm 0,011^{\text {a) }}$ \\
\hline
\end{tabular}

Laju pertumbuhan spesifik ikan betutu (Oxyeleotris marmorata. Blkr.) dengan jenis wadah yang berbeda selama 120 hari pengamatan.

Keterangan: $\mathrm{A}=$ kolam tanah; $\mathrm{B}=$ kolam hapa; $\mathrm{C}=$ kolam terpal; $\pm \mathrm{SD}=$ standar deviasi yang merupakan range dari rata-rata pengulangan masing-masing perlakuan; huruf superskrip a) = menunjukkan adanya perbedaan signifikan berdasarkan uji Anova yang dilanjutkan dengan Tukey test $(\alpha=0,05)$. 
Laju pertumbuhan spesifik tertinggi dicapai pada perlakuan kolam tanah yaitu $0,45 \pm 0,010 \% /$ hari, di ikuti kolam hapa $0,42 \pm 0,013 \% /$ hari dan kolam terpal $0,40 \pm 0,011 \% /$ hari. Hasil Anova menunjukkan bahwa penggunaan jenis wadah yang berbeda berpengaruh signifikan terhadap pertambahan bobot ikan betutu ( $F$ hitung 33,91 > F tabel $(0,05) 5,78$ ). Hasil uji lanjut menggunakan Tukey test menunjukkan bahwa seluruh perlakuan penelitian menunjukkan adanya perbedaan yang signifikan $(\alpha=0,05)$.

\subsubsection{Kelangsungan hidup ikan betutu (Oxyeleotris marmorata Blkr.)}

Kelangsungan hidup adalah perbandingan jumlah ikan yang hidup pada akhir penelitian dengan jumlah ikan uji pada awal penelitian yang dinyatakan dalam persen (Effendie, 2002). Hasil pengamatan terhadap tingkat kelangsungan hidup ikan betutu pada masing-masing unit percobaan penelitian dapat dilihat pada Tabel 4.

Tabel 4

Tingkat kelangsungan hidup ikan betutu (Oxyeleotris marmorata. Blkr.) dengan jenis wadah yang berbeda selama 120 hari pengamatan.

\begin{tabular}{lcccc}
\hline Perlakuan & \multicolumn{4}{c}{ Kelangsungan hidup } \\
\cline { 2 - 5 } & $\begin{array}{c}\text { Kolam 1 } \\
\text { (ekor) }\end{array}$ & $\begin{array}{c}\text { Kolam 2 } \\
\text { (ekor) }\end{array}$ & $\begin{array}{c}\text { Kolam 3 } \\
\text { (ekor) }\end{array}$ & $\begin{array}{c}\text { Survival Rate } \\
(\%)\end{array}$ \\
\hline A & 23 & 21 & 20 & $85,33 \pm 6,11$ \\
B & 22 & 19 & 21 & $82,67 \pm 6,11$ \\
C & 20 & 17 & 18 & $73,33 \pm 6,11$ \\
\hline
\end{tabular}

Keterangan: $\mathrm{A}=$ kolam tanah; $\mathrm{B}=$ kolam hapa; $\mathrm{C}=$ kolam terpal; $\pm \mathrm{SD}=$ standar devias yang merupakan range dari rata-rata pengulangan masing-masing perlakuan; SR = survival rate merupakan persentase tingkat kelangsungan hidup ikan pada saat akhir penelitian.

Tingkat kelangsungan hidup tertinggi dicapai pada perlakuan kolam tanah yaitu $85,33 \pm 6,11 \%$, di ikuti kolam hapa $82,67 \pm 6,11 \%$ dan kolam terpal $73,33 \pm 6,11 \%$. Hasil Anova menunjukkan bahwa jenis wadah yang berbeda tidak berpengaruh terhadap tingkat kelangsungan hidup ikan betutu ( $F$ hitung $3,19<\mathrm{F}$ tabel $(0,05) 5,78)$.

\subsubsection{Kualitas air}

Parameter kualitas air yang diukur dalam penelitian ini adalah suhu, $\mathrm{pH}$, oksigen terlarut dan amonia. Hasil pengukuran Kualitas air selama penelitian disajikan pada Tabel 5.

Tabel 5

Kualitas air pada seluruh unit perlakuan penelitian selama 120 hari pengamatan.

\begin{tabular}{lcccc}
\hline \multirow{2}{*}{ Perlakuan } & \multicolumn{4}{c}{ Parameter } \\
\cline { 2 - 5 } & Suhu $\left({ }^{\circ} \mathrm{C}\right)$ & $\mathrm{pH}$ & $\mathrm{DO}(\mathrm{mg} / \mathrm{L})$ & $\begin{array}{c}\text { Amonia } \\
(\mathrm{mg} / \mathrm{L})\end{array}$ \\
\hline $\mathrm{A}$ & $27,07 \pm 0,23$ & $6,85 \pm 0,26$ & $3,62 \pm 0,35$ & $0,041 \pm 0,04$ \\
$\mathrm{~B}$ & $27,04 \pm 0,25$ & $6,80 \pm 0,28$ & $3,54 \pm 0,37$ & $0,057 \pm 0,02$ \\
$\mathrm{C}$ & $27,38 \pm 0,26$ & $6,72 \pm 0,42$ & $3,47 \pm 0,35$ & $0,098 \pm 0,03$ \\
Kisaran optimal & $24-28{ }^{\circ} \mathrm{C}^{\mathrm{a})}$ & $5,5-7,5^{\mathrm{b})}$ & $>3 \mathrm{mg} / \mathrm{L}^{\mathrm{b})}$ & $<2 \mathrm{mg} / \mathrm{L}^{\mathrm{c})}$ \\
\hline
\end{tabular}

Keterangan: $\mathrm{A}=$ kolam tanah; $\mathrm{B}=$ kolam hapa; $\mathrm{C}=$ kolam terpal; $\pm \mathrm{SD}=$ standar deviasi yang merupakan range dari rata-rata pengulangan masing-masing perlakuan; huruf superskrip ${ }^{a)}=$ kisaran optimal menurut Azwar, et al (2003); ${ }^{\text {b) }}=$ kisaran optimal menurut Kordi (2013); c) kisaran optimal menurut Hidayah (1993).

Hasil pengukuran kualitas air menunjukkan bahwa kualitas air masih dalam kondisi yang baik untuk budidaya ikan betutu. Hasil pengukuran terhadap parameter suhu di peroleh nilai rata-rata $27,16 \pm 0,29{ }^{\circ} \mathrm{C}, \mathrm{pH} 6,79 \pm 0,32$, DO 3,54 $\pm 0,35 \mathrm{mg} / \mathrm{L}$ dan ammonia $0,065 \pm 0,03 \mathrm{mg} / \mathrm{L}$. Nilai parameter perairan yang di ukur pada masing-masing wadah budidaya sebagai unit percobaan masih dalam kisaran nilai optimal dalam mendukung kehidupan ikan betutu (Azwar et al., 2003; Kordi, 2013; Hidayah, 1993).

\subsection{Pembahasan}

Pertambahan bobot rata-rata ikan betutu sebagai ikan uji yang dipelihara selama 120 hari pada wadah yang berbeda (kolam tanah, kolam hapa dan kolam terpal) relatif bervariasi. Hasil pengamatan menunjukkan bobot rata-rata ikan betutu pada setiap wadah meningkat seiring dengan lamanya pemeliharaan. Pada akhir masa pemeliharaan, wadah yang menghasilkan pertambahan bobot rata-rata tertinggi adalah kolam tanah $53,86 \pm 1,10 \mathrm{~g}$, disusul kolam hapa dengan pertambahan bobot $50,56 \pm 1,65 \mathrm{~g}$ dan pertambahan bobot pada kolam terpal menghasilkan pertambahan bobot terendah $48,26 \pm 1,47 \mathrm{~g}$. Hasil Tukey test menunjukkan bahwa pertambahan bobot tertinggi pada kolam tanah berbeda nyata dengan pertambahan bobot pada kolam hapa dan kolam terpal. Hasil penelitian ini memperlihatkan pertambahan bobot yang lebih baik dibandingkan Azwar dan Melati (2011) yang mendapati pertambahan bobot ikan betutu sebesar $26,93 \pm 2,15 \mathrm{~g}$ yang dipelihara selama 60 hari dengan frekwensi pemberian pakan berupa Tubifex $s p$. beku secara ad satiasi dua kali sehari. Hasil yang lebih baik didapati pada perlakuan padat tebar ikan betutu pada lokasi yang sama oleh Harahap dan Yusapri (2016) yang melaporkan pertambahan bobot ikan betutu yang dipelihara dalam kolam hapa selama 60 hari berada pada kisaran 27,04$57,22 \mathrm{~g}$.

Hasil penelitian ini analog dengan penelitian penggunaan wadah budidaya yang berbeda pada ikan gabus (Channa striata) oleh Heriansah dan Aspari, (2016) yang memperlihatkan kinerja pertambahan bobot tertinggi didapati pada perlakuan kolam tanah dibandingkan dengan kolam beton dan kolam terpal. Pertambahan bobot ikan gabus pada kolam tanah diketahui $20,24 \%$ lebih baik dibandingkan dengan kolam beton dan $22,02 \%$ lebih baik dibandingkan kolam terpal. Selaras dengan hasil penelitian ini, perbedaan wadah budidaya terhadap pertambahan bobot ikan gabus memperlihatkan adanya perbedaan yang nyata antar perlakuan penelitian (Heriansah dan Aspari, 2016).

Parameter laju pertumbuhan spesifik ikan betutu juga memperlihatkan kondisi yang relatif sama dengan pertambahan bobot. Laju pertumbuhan spesifik menjelaskan kemampuan ikan dalam memanfaatkan nutrien untuk disimpan dalam tubuh dan mengkonversinya menjadi energi (Widyati dalam Anggraeni dan Abdulgani, 2013). Kolam tanah memperlihatkan laju pertumbuhan spesifik tertinggi dengan nilai (SGR) $0,45 \pm 0,010$ \%berat tubuh/hari, disusul kolam hapa (SGR) 0,42 $\pm 0,013 \%$ berat tubuh/hari dan kolam terpal dengan nilai (SGR) terendah 0,40 $\pm 0,011$ \%berat tubuh/hari. Hasil Tukey test terhadap laju pertumbuhan spesifik menunjukkan adanya perbedaan yang signifikan antar perlakuan penelitian. Harahap dan Yusapri, (2015) melaporkan bahwa rata-rata laju pertumbuhan spesifik ikan betutu yang dipelihara dalam kolam hapa selama 120 hari dengan pemberian pakan ikan rucah secara ad libitum sebesar 1,672 \%bobot tubuh/hari. Sedangkan Ahlina et al. (2018) melaporkan bahwa perbedaan frekwensi pemberian pakan pada ikan betutu menghasilkan laju pertumbuhan spesifik antara 0,49$0,54 \%$ bobot tubuh/hari pada lokasi penelitian yang sama.

Hasil penelitian yang menunjukkan laju pertumbuhan spesifik terbaik yang dihasilkan oleh perlakuan kolam tanah di dukung oleh penelitian Heriansah et al. (2016) yang mendapati laju pertumbuhan spesifik ikan gabus pada kolam tanah lebih baik $0,12 \%$ dibandingkan kolam beton dan 0,27\% lebih baik dibandingkan kolam terpal. Perbedaan wadah budidaya juga 
memperlihatkan respon yang berbeda nyata terhadap laju pertumbuhan spesifik ikan gabus (Heriansah dan Aspari, 2016).

Perbedaan pertambahan bobot dan laju pertumbuhan spesifik ikan betutu pada masing-masing perlakuan penelitian diduga dipengaruhi oleh faktor internal dan eksternal. Menurut Prihadi et al. (2018) pertumbuhan ikan sangat dipengaruhi oleh faktor internal antara lain genetik, aktifitas, spesies, jenis kelamin, umur dan ukuran ikan, kondisi fisiologi; sedangkan faktor eksternal berkaitan dengan lingkungan tempat hidup ikan. Faktor internal yang mempengaruhi pertambahan bobot dan pertumbuhan spesifik ikan betutu diduga disebabkan oleh faktor biologis berupa kebiasaan ikan betutu yang senang tidur dan berdiam diri di dasar perairan. Ikan betutu dikenal memiliki karakteristik malas, bahkan dijuluki sebagai the sleeper fish karena ikan ini memiliki sifat malas, senang tidur dan berdiam diri di dasar perairan (Larson, 2000). Pada kolam tanah ikan betutu dapat membenamkan diri secara langsung di dasar perairan, sedangkan pada kolam hapa dan kolam terpal kontak langsung terhadap dasar perairan tidak dapat terjadi secara sempurna. Terganggunya kebiasaan dan aktifitas alamiah ikan betutu dapat menjadi pemicu perubahan terhadap fisiologis ikan yang akan menyebabkan ikan menjadi stress. Kondisi ini akan menyebabkan menurunnya nafsu makan yang akan berdampak pada terhambatnya pertumbuhan (Ardi et al., 2017).

Faktor eksternal yang mempengaruhi pertambahan bobot dan pertumbuhan spesifik ikan betutu adalah faktor lingkungan perairan berupa parameter fisika, kimia dan biologi perairan. Hasil pengukuran kualitas air pada masing-masing wadah didapati suhu berada pada kisaran $27,07-27,38{ }^{\circ} \mathrm{C}, \mathrm{pH}$ $(6,72-6,85)$, DO $(3,47-3,62 \mathrm{mg} / \mathrm{L})$ dan ammonia $(0,11-0,18$ $\mathrm{mg} / \mathrm{L})$. Kondisi kualitas air ini sesuai dengan Harahap dan Yusapri (2016) yang melaporkan nilai parameter suhu antara $26-27^{\circ} \mathrm{C}$, $\mathrm{pH} 6,71-7,20$ dan DO 3-4 mg/L pada lokasi yang sama. Ahlina et al. (2017) juga melaporkan bahwa nilai parameter $\mathrm{pH}$ air pada kolam percobaan memiliki kisaran nilai 6,0-7,2 dan 3-4 mg/L untuk parameter DO.

Kondisi kualitas air pada seluruh wadah perlakuan masih memperlihatkan kondisi optimal dalam mendukung kehidupan betutu. Meskipun demikian fluktuasi nilai parameter kualitas air pada masing-masing wadah perlakuan memperlihatkan nilai yang variatif. Kolam tanah dan kolam hapa menunjukkan kondisi kualitas air yang lebih stabil dibandingkan kolam terpal. Suhu pada kolam terpal relatif lebih tinggi dibandingkan kolam tanah dan kolam hapa. Kondisi ini diduga disebabkan oleh efek penyinaran matahari. Kolam tanah dan kolam hapa cenderung lebih baik dalam menyimpan panas sehingga mampu menjaga suhu kolam agar relatif stabil dibandingkan kolam terpal dimana air tidak bersentuhan langsung dengan tanah dasar perairan (Heriansah \& Aspari, 2016). Menurut Azwar et al. (2003) suhu air yang cocok bagi pertumbuhan benih ikan betutu adalah 24-28ㅇ, sedangkan bagi indukan ikan betutu dapat hidup pada suhu 30 ㄷ. Produktivitas tertinggi benih ikan betutu didapati pada kisaran suhu $29-32^{\circ} \mathrm{C}$ yaitu sebesar 0,99 sampai dengan 1,09 g/hari (Taufik et al., 2009).

Nilai pH pada kolam terpal relatif lebih rendah dibandingkan kolam tanah dan hapa. Efek karakteristik kolam terpal yang tidak bersentuhan langsung dengan tanah dasar perairan diduga menjadi penyebab menurunnya nilai $\mathrm{pH}$ terutama saat mendekati akhir masa pemeliharaan. Secara alamiah konsentrasi $\mathrm{pH}$ dipengaruhi oleh tanah dasar perairan yang menghasilkan konsentrasi $\mathrm{pH}$ di kolam tanah cenderung lebih stabil dibanding pada kolam terpal (Heriansah dan Aspari, 2016). Leong et al. (2015) menyatakan bahwa ikan betutu dapat hidup dengan baik pada pH 7,5-8,5. Sedangkan Kordi (2013) menyatakan bahwa kisaran $\mathrm{pH}$ 5,5-6,5 ikan betutu masih bisa hidup dan tumbuh, namun ikan betutu bisa tumbuh dengan baik pada kisaran $\mathrm{pH}$ 7,0-7,5.

Kondisi yang sama juga terjadi pada parameter DO pada kolam terpal yang menunjukkan kisaran nilai yang relatif lebih rendah dibanding kolam tanah dan hapa. Perbedaan nilai DO diduga disebabkan efek cahaya matahari sebagai energi bagi plankton dalam proses fotosintesis untuk menghasilkan oksigen (Prihadi, 2018). Pada dasar perairan kolam tanah dan hapa kandungan bahan anorganik relatif tinggi dibanding pada kolam terpal. Kondisi ini menjadikan fitoplankton akan mengubah bahan anorganik menjadi bahan organik melalui proses fotosintesis yang akan menghasilkan DO di perairan (Mulyanto dalam Adani et al., 2013). Ardi et al. (2016) mengemukakan bahwa DO yang baik untuk budidaya ikan betutu berkisar antara 0,366-0,47 mg/L. Ikan betutu masih bisa bertahan hidup dalam perairan dengan kandungan oksigen terlarut yang rendah yaitu 2 $\mathrm{mg} / \mathrm{L}$ dan betutu tumbuh dengan baik dalam perairan dengan kandungan oksigen terlarut $>3 \mathrm{mg} / \mathrm{L}$ (Kordi, 2013).

Nilai konsentrasi ammonia pada kolam terpal relatif lebih tinggi dibanding kolam tanah dan kolam hapa. Kondisi ini memperlihatkan bahwa proses perombakan sisa pakan dan metabolisme pada kolam tanah dan kolam hapa berlangsung lebih baik dibanding kolam terpal. Ammonia merupakan produk hasil metabolisme ikan dan dekomposisi senyawa organik seperti sisa-sisa pakan dan kotoran ikan oleh bakteri menjadi nitrogen dalam bentuk ammonium terlarut (Hidayah, 1993). Pada kolam terpal, air dan tanah dasar kolam tidak bersentuhan secara langsung yang mengakibatkan proses dekomposisi bahan organik oleh bakteri tidak berlangsung secara optimal. Meskipun demikian nilai kisaran konsentrasi ammonia yang didapati pada penelitian ini masih dalam kisaran ambang batas ammonia untuk ikan air tawar yaitu $<2 \mathrm{mg} / \mathrm{L}$ (Hidayah, 1993). Sedangkan menurut pendapat Kordi (2013) ikan betutu masih dapat hidup optimum pada perairan yang mengandung ammonia antara 0,556-0,779 $\mathrm{mg} / \mathrm{L}$. Konsentrasi ammonia akan cenderung semakin meningkat seiring meningkatnya nilai suhu dan $\mathrm{pH}$ perairan. Nilai $\mathrm{pH}>7$ akan menyebabkan ammonia tak terionisasi terutama pada kolam terpal yang tidak bersentuhan langsung terhadap tanah dasar perairan. Kondisi ini akan menyebabkan ammonia bersifat toksik terhadap organisme akuatik apabila terdapat dalam jumlah banyak. Toksisitas ammonia terhadap organisme akuatik akan meningkat jika terjadi penurunan nilai suhu, pH dan kadar DO perairan (Effendi, 2003).

Perbedaan wadah pemeliharaan berupa kolam tanah, kolam hapa dan kolam terpal pada penelitian ini tidak berpengaruh nyata terhadap kelangsungan hidup ikan betutu $(P>0,05)$. Kondisi ini menggambarkan bahwa perlakuan jenis wadah pemeliharaan kolam tanah, kolam hapa dan kolam terpal masih mendukung pertumbuhan dan kelangsungan hidup ikan betutu. Hal ini selaras dengan hasil pemantauan terhadap parameter kualitas air pada masing-masing wadah pemeliharaan yang juga masih memperlihatkan kisaran nilai optimal dalam mendukung pertumbuhan dan kelangsungan hidup ikan betutu.

\section{Kesimpulan}

Berdasarkan hasil penelitian dapat disimpulkan bahwa:

1. Perbedaan jenis wadah berpengaruh nyata terhadap pertambahan bobot dan laju pertumbuhan spesifik, namun tidak berpengaruh nyata terhadap kelangsungan hidup ikan betutu.

2. Pertambahan bobot terbaik ikan betutu terdapat pada perlakuan jenis wadah kolam tanah yaitu $53,86 \pm 1,10 \mathrm{~g}$, laju pertumbuhan spesifik (SGR) $0,45 \pm 0,010 \%$ bobot tubuh/hari dengan nilai kelangsungan hidup (SR) $85,33 \pm 6,11 \%$. 
3. Pertambahan bobot dan laju pertumbuhan spesifik ikan betutu pada kolam tanah berbeda nyata dengan kolam hapa dan kolam terpal. Demikian pula pertambahan bobot dan laju pertumbuhan spesifik ikan betutu pada kolam hapa berbeda nyata dengan kolam terpal.

4. Nilai parameter kualitas air pada seluruh wadah pemeliharaan masih mendukung pertumbuhan dan kelangsungan hidup ikan betutu dengan kisaran suhu $27,38 \pm 0,26-27,07 \pm 0,23{ }^{\circ} \mathrm{C}$, pH 6,72 $\pm 0,42-6,85 \pm 0,26$, DO $3,47 \pm 0,35-3,62 \pm 0,35 \mathrm{mg} / \mathrm{L}$ dan ammonia $0,098 \pm 0,03 \mathrm{mg} / \mathrm{L}$.

\section{Ucapan penghargaan}

Penelitian ini didukung oleh hibah Penelitian Dosen Pemula Direktorat Jenderal Penguatan Riset dan Pengembangan Kementerian Riset, Teknologi, dan Pendidikan Tinggi (Kemenristek-Dikti) tahun 2019 yang disalurkan melalui Lembaga Penelitian dan Pengabdian Masyarakat (LPPM) Universitas Islam Indragiri (UNISI). Untuk itu penulis mengucapkan terima kasih kepada Kemenristek-Dikti dan LPPM UNISI. Ucapan yang sama disampaikan pula kepada Kepala dan tenaga laboran Laboratorium Basah Program Studi Budidaya Perairan, kepada pengelola jurnal Acta Aquatica: Aquatic Sciences Journal yang telah berkenan mempublikasikan hasil penelitian ini dan semua pihak yang telah membantu penelitian ini.

\section{Bibliografi}

Adani, N.G., Hendrarto, B., Muskanonfola, M.R., 2013. Kesuburan Perairan Ditinjau dari Kandungan Klorofil-a Fitoplankton: Studi Kasus di Sungai Wedung, Demak. Management of Aquatic Resources Journal, Vol. 2(4): 38-45.

Ahlina, H.F., Sawitri, N., Harahap, S.R., 2018. Kinerja Pertumbuhan dan Kelulushidupan Ikan Betutu (Oxyeleotris marmorata. Blkr.) yang Diberi Pakan Ikan Rucah Dengan Frekwensi Berbeda. Jurnal Perikanan dan Lingkungan, Vol. 7(2): 1-9.

Anggraeni, N.M., Abdulgani, N., 2013. Pengaruh Pemberian Pakan Alami dan Pakan Buatan Terhadap Pertumbuhan Ikan Betutu (Oxyeleotris marmorata) pada Skala Laboratorium. Jurnal Sains dan Seni ITS, Vol. 2(2): E197E201.

Ardi, I., Setiadi, E., Kristanto, A.H., Widiyati, A., 2017. Salinitas Optimal untuk Pendederan Benih Ikan Betutu (Oxyeleotris Marmorata). Jurnal Riset Akuakultur, Vol. 11(4): 347-354.

Arief, M., Triasih, I., Lokapirnasari, W.P., 2009. Pengaruh Pemberian Pakan Alami dan Pakan Buatan terhadap Pertumbuhan Benih Ikan Betutu (Oxyeleotris marmorata Bleeker). Jurnal IImiah Kelautan dan Perikanan UNAIR, Vol. 1(1): 51-57.

Azwar, Z.I., Arifin, O., Pamungkas, W., Yosmaniar, 2003. Pengelolaan Produksi Massal Ikan Betutu (Oxyeleotris marmoratus, Bleeker) Balai Riset Perikanan Budidaya Air Tawar. Balai Riset Kelautan dan Perikanan. Departemen Kelautan dan Perikanan. Hal. 77-184.

Azwar, Z.I., Melati, I., 2011. Frekwensi Pemberian Pakan dan Teknologi Produksi Ikan Betutu (Oxyeleotris Marmorata
Blkr.) dengan Sistem Terkontrol. Jurnal Riset Akuakultur, Vol. 6(3): 447-456.

Effendi, H., 2003. Telaah Kualitas Air, Bagi Pengelolaan Sumber Daya dan Lingkungan Perairan. Kanisius.

Effendie, M.I., 2002. Biologi Perikanan Ed ke-2 (Edisi Revisi). Yayasan Pustaka Nusatama. Yogyakarta.

Elliot, J.M., Hurley, M.A., 1995. Function Ecology. British Ecological Society, British, Vol. 9: 625-627.

Harahap, S.R., Yusapri, A., 2015. Pengaruh Pemberian Pakan Berbeda Terhadap Pertumbuhan Ikan Betutu (Oxyeleotris marmorata. Blkr.) dalam Jaring Hapa. Jurnal Terubuk, Vol. 43(1): 1-11.

Harahap, S.R., Yusapri, A., 2016. Pengaruh Padat Penebaran Berbeda Terhadap Kelulushidupan dan Pertumbuhan Ikan Betutu (Oxyeleotris marmorata. Blkr.) yang Dipelihara Dalam Hapa. Jurnal Perikanan dan Lingkungan, Vol. 5(2).

Heriansah, Aspari, D.N.F., 2016. Kinerja Pertumbuhan Ikan Gabus (Channa striata) dan Dinamika Kualitas Air Pada Berbaga Wadah Pemeliharaan. Jurnal Balik Diwa, Vol. 7(2): 15-21.

Hidayah, Z., 1993. Pengaruh Pemberian Pakan Buatan Terhadap Pertumbuhan dan Kelangsungan Hidup Larva Ikan Betutu (Oxyeleotris marmorata Blkr) yang Dipelihara di Kolam. Skripsi Program Studi Budidaya Perairan Fakultas Perikanan Institut Pertanian Bogor. Bogor. $60 \mathrm{hlm}$.

Kordi, M.G.H., 2013. Panduan Lengkap Bisnis dan Budidaya Ikan Betutu. Lily Publisher Yogyakarta. $226 \mathrm{hlm}$.

Kudsiah, H., Nur, A., 2008. Efisiensi Usaha Pembesaran Ikan Betutu Dengan Pemberian Berbagai Bentuk Pakan dari Ikan Sepat Rawa dan Udang Rucah. Jurnal Sains dan Teknologi Vol. 8.

Larson, H.K., 2000. Gobbidae (Gobies and Sleepers), P. 636-640. In J.E. Randall and K.K.P Lim (eds). A Checklist of the fishers of the South China Sea Raffles Bull. 2001. 181: 569-667.

Leong, L.P., Chong, V.C dan Ibrahim, S., 2015. Manipulating Culture Conditions and Feed Quality to Increase the Survival of Larval Marble Goby (Oxyeleotris marmoratus, Bleeker). University of Malaya. Kuala Lumpur. Malaysia.

Prihadi, T.H., Saputra, A., Huwoyon, G.H., Pantjara, B., 2018. Pengaruh Kepadatan Terhadap Sintasan, Pertumbuhan, dan Gambaran Darah Benih Ikan Betutu Oxyeleotris marmorata. Jurnal Riset Akuakultur, Vol. 12(4): 341-350.

Saparinto, C., 2009. Budi Daya Ikan di Kolam Terpal (Revisi). Penebar Swadaya Grup. Jakarta.

Satyani, D., Priono, B., 2012. Penggunaan Berbagai Wadah Untuk Pembudidayaan Ikan Hias Air Tawar. Media Akuakultur, Vol. 7(1): 14-19.

Taufik, I., Azwar, Z.I., Sutrisno, 2009. Ikan Betutu (Oxyeleotris marmoratus, Bleeker) Dengan Sistem Resikulasi. Jurnal Riset Akuakultur, Vol. 4(3). 